\title{
Synthesis and First Hyperpolarizabilities of Acceptor-substituted $\beta$-apo-8'-Carotenal Derived Compounds
}

\author{
Sandra Gilmour, $a$ Seth R. Marder, ${ }^{a, b}$ Bruce G. Tiemann $a, b$ and Lap-Tak Cheng $c$ \\ a Jet Propulsion Laboratory, California Institute of Technology, 4800 Oak Grove Drive, Pasadena, CA 91109, USA \\ b Molecular Materials Resource Center, The Beckman Institute, California Institute of Technology, Pasadena, CA 91125. \\ USA \\ c Central Research and Development Department, E. I. Du Pont de Nemours \& Co. Inc., Experimental Station, PO Box \\ 80356, Wilmington, Delaware 19880-0356, USA
}

The synthesis and second-order nonlinear optical properties of acceptor-substituted biologically derived $\beta$-apo-8'-carotenal compounds are reported; electric field-induced second harmonic generation (EFISH) measurements give values of $\beta(0)$ which are 2-6 times greater than for $4-N, N$-dimethylamino-4'-nitrostilbene (DANS).

In an attempt to understand the structural basis of molecular polarizabilities and hyperpolarizabilities in conjugated organic chromophores we have been investigating the parameters of bond length alternation (BLA) and aromaticity. ${ }^{1-3}$ Computational studies using MOPAC, 4.5 together with experimental electric field-induced second harmonic generation (EFISH) ${ }^{6,7}$ and third harmonic generation (THG) results on asymmetric cyanines and polarized polyenes have lead us to believe that there is a specific amount of BLA (the difference in length between the carbon double and single bonds in a conjugated chain) which can maximize the molecular polarizability $(\alpha)$, the first hyperpolarizability $(\beta)^{1,3.8}$ or the second hyperpolarizability $(\gamma)^{9}$ for a given molecular length. Experimental and theoretical evidence ${ }^{1,3.9}$ points to the fact that $\alpha$ is maximized when BLA is zero, and that $\beta$ is peaked at a value of around $0.04 \AA$. Calculations for relatively short systems, also predict that positive $\gamma$ is peaked at greater BLA than for $\beta$, and that negative $\gamma$ is maximized at zero BLA.

At present most donor-acceptor nonlinear optical chromophores in their ground-state contain aromatic groups, which from simple resonance structure considerations become quinoidal when the molecule is in its charge-separated state. Investigations on a typical neutral donor-acceptor substituted

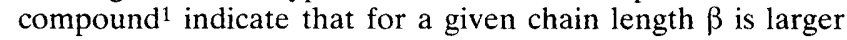
when the molecule does not have to lose aromaticity upon charge-transfer polarization. As aromaticity is stabilizing, its loss upon charge-separation could hinder efficient chargetransfer polarization.

We wished to probe the effects of aromaticity and the introduction of ground- and excited-state dipole moments on both the second-and third-order hyperpolarizabilities of a series of compounds very closely related to the well-studied molecule, $\beta$-carotene. ${ }^{10}$ Blanchard-Desce and coworkers ${ }^{11-13}$ have investigated the nonlinear optical properties of some
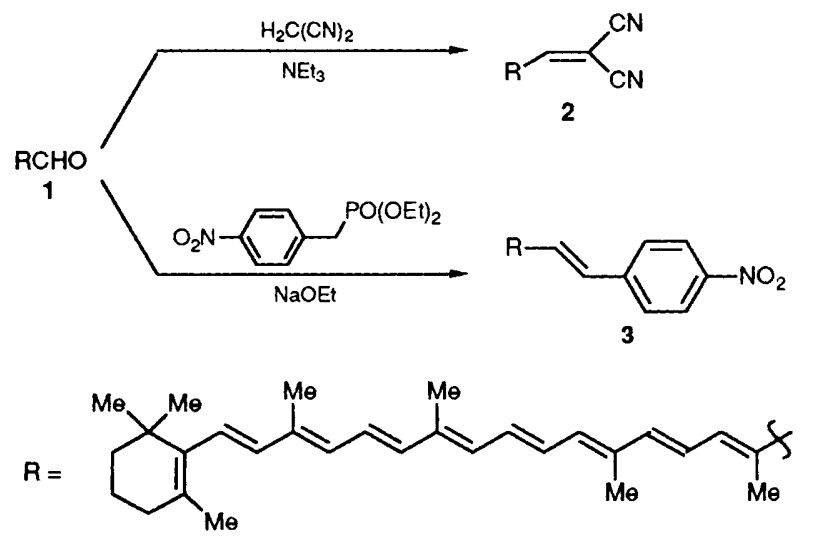

Scheme 1 Synthesis of acceptor-substituted $\beta$-apo- $8^{\prime}$-carotenoid compounds 
Table 1 Selected linear and nonlinear optical properties in chloroform of substituted $\beta$-apo- $8^{\prime}$-carotenoids in Scheme 1

\begin{tabular}{|c|c|c|c|c|c|c|}
\hline Compound & $\lambda_{\max } / \mathrm{nm}$ & $\begin{array}{l}\varepsilon / \mathrm{dm}^{3} \\
\mathrm{~mol}^{-1} \mathrm{~cm}^{-1}\end{array}$ & $\mu / 10^{-18}$ esu & $\beta / 10^{-30}$ esu & $\beta(0) / 10^{-30} \mathrm{esu}$ & $\mu \cdot \beta / 10^{-48}$ esu \\
\hline 1 & 476 & 89000 & 6.5 & 147 & 104 & 956 \\
\hline 2 & 566 & 98200 & 7.7 & 570 & 337 & 4389 \\
\hline 3 & 502 & 95700 & 7.0 & 220 & 148 & 1540 \\
\hline
\end{tabular}

related compounds with chain lengths shorter than and equal to $\beta$-apo- 8 -carotenal, 1 (Scheme 1 ), substituted with a series of donors and an aldehyde acceptor, and Ikeda and coworkers $^{14}$ have examined a series of retinal-derived compounds. In this contribution we report on the synthesis and second-order nonlinear optical properties of $\beta$-apo- $8^{\prime}-$ carotenal derivatives with terminal acceptor substituents, whose structures are more closely related to $\beta$-carotene than those in the previous studies. ${ }^{11-14}$

The new compounds were readily synthesized (Scheme 1) using standard Knoevenagel ${ }^{15}$ conditions for the synthesis of 2 and Wadsworth-Emmons ${ }^{16}$ conditions for 3 . The compounds were purified by chromatography on silica, recrystallized and then characterized by UV-VIS, ${ }^{1} \mathrm{H}$ and ${ }^{1} \mathrm{H}$ COSY NMR and mass spectroscopy, as well as elemental analysis. $\dagger \beta$ values were measured in chloroform solution by EFISH using 1.907 $\mu \mathrm{m}$ fundamental radiation. ${ }^{6.7}$

Table 1 shows values of the optical absorption maximum $\left(\lambda_{\max }\right)$, the extinction coefficient $(\varepsilon)$, the dipole moment $(\mu)$, first hyperpolarizability $(\beta)$, the zero frequency form of $\beta[\beta(0)]$ corrected for dispersion using a two-state model ${ }^{17}$ and the dot product of $\beta$ and $\mu(\mu \cdot \beta)$, which of interest in poled polymer applications. Although these chromophores have no heteroatom donor, their hyperpolarizabilities are reasonably large, with each having a $\beta(0)$ significantly larger than that of the prototypical stilbene compound 4-N,N-dimethylamino- $4^{\prime}$ nitrostilbene (DANS) $\left[\beta(0)=55 \times 10^{-30} \mathrm{esu}\right]$. These rather large nonlinearities can be explained by the large intrinsic polarizability of the extended $\pi$-electron system. For polyenes, the HOMO-LUMO gap decreases with increasing conjugation length resulting from the energy of the LUMO being lowered and that of the HOMO being raised. In molecular orbital terms, a donor is a high lying occupied orbital, and thus, in long polyenes, the HOMO itself can act as a donor. As the length of the conjugated chain is increased, the HOMO becomes a more effective donor.

Dicyanovinyl groups are stronger acceptors than aldehydes, and this is reaffirmed by compound 2 having a $\beta(0)$ value of over three times greater than for compound 1 . Nitro groups are also stronger acceptors than aldehydes, but on looking at the $\beta(0)$ value for $\mathbf{3}$ it is not substantially greater than for $\mathbf{1}$,

$\dagger$ Characterizing data for 2: Yield, $15 \%$. M.p., $184-186^{\circ} \mathrm{C} .{ }^{1} \mathrm{H}$ and ${ }^{1} \mathrm{H}$ COSY NMR $\left(\mathrm{CD}_{2} \mathrm{Cl}_{2}\right) \delta 1.03(\mathrm{~s}, 6 \mathrm{H}), 1.47(\mathrm{~m}, 2 \mathrm{H}), 1.62(\mathrm{~m}, 2 \mathrm{H})$, $1.72(\mathrm{~s}, 3 \mathrm{H}), 1.99(\mathrm{~s}, 3 \mathrm{H}), 2.00(\mathrm{~s}, 3 \mathrm{H}), 2.02(\mathrm{~s}, 3 \mathrm{H}), 2.03(\mathrm{~m}, 2 \mathrm{H})$, $2.27(\mathrm{~s}, 3 \mathrm{H}), 6.15(\mathrm{~d}, 1 \mathrm{H}, J 15.86 \mathrm{~Hz}), 6.18(\mathrm{~d}, 1 \mathrm{H}, J 10.40 \mathrm{~Hz}), 6.24$ $(\mathrm{d}, 1 \mathrm{H}, J 16.04 \mathrm{~Hz}), 6.31(\mathrm{~d}, 1 \mathrm{H}, J 11.93 \mathrm{~Hz}), 6.39(\mathrm{~d}, 1 \mathrm{H}, J 14.96 \mathrm{~Hz})$, $6.54(\mathrm{~d}, 1 \mathrm{H}, J 11.63 \mathrm{~Hz}), 6.64(\mathrm{dd}, 1 \mathrm{H}, J 14.76,11.54 \mathrm{~Hz}), 6.68(\mathrm{dd}$, $1 \mathrm{H}, J 13.91,12.18 \mathrm{~Hz}), 6.78(\mathrm{dd}, 1 \mathrm{H}, J 14.93,11.43 \mathrm{~Hz}), 6.86(\mathrm{dd}, 1 \mathrm{H}$, $J 13.75,12.12 \mathrm{~Hz}), 6.80(\mathrm{~d}, 1 \mathrm{H}, J 11.56 \mathrm{~Hz}), 6.81(\mathrm{~d}, 1 \mathrm{H}, J 14.86 \mathrm{~Hz})$, $7.26(\mathrm{~s}, 1 \mathrm{H})$. Satisfactory elemental analyses were obtained. Highresolution EIMS, $m / z$ calc. for $\mathrm{C}_{33} \mathrm{H}_{40} \mathrm{~N}_{2} ; 465.3270$. Found: 465.3243 .

Characterizing data for 3: Yield, $37 \%$. M.p., $296-300{ }^{\circ} \mathrm{C} .{ }^{1} \mathrm{H}$ and ${ }^{1} \mathrm{H}$ COSY NMR $\left(\mathrm{CD}_{2} \mathrm{Cl}_{2}\right) \delta 1.03(\mathrm{~s}, 6 \mathrm{H}), 1.47(\mathrm{~m}, 2 \mathrm{H}), 1.62(\mathrm{~m}, 2 \mathrm{H})$, $1.72(\mathrm{~s}, 3 \mathrm{H}), 1.98(\mathrm{~s}, 3 \mathrm{H}), 1.99(\mathrm{~s}, 3 \mathrm{H}), 2.00(\mathrm{~s}, 3 \mathrm{H}), 2.03(\mathrm{~m}, 2 \mathrm{H})$, $2.07(\mathrm{~s}, 3 \mathrm{H}), 6.14(\mathrm{~d}, 1 \mathrm{H}, J 15.90 \mathrm{~Hz}), 6.16(\mathrm{~d}, 1 \mathrm{H}, J 9.08 \mathrm{~Hz}), 6.21(\mathrm{~d}$, $1 \mathrm{H}, J 16.22 \mathrm{~Hz}), 6.28(\mathrm{~d}, 1 \mathrm{H}, J 10.61 \mathrm{~Hz}), 6.35(\mathrm{~d}, 1 \mathrm{H}, J 10.49 \mathrm{~Hz})$, $6.37(\mathrm{~d}, 1 \mathrm{H}, J 14.87 \mathrm{~Hz}), 6.47(\mathrm{~d}, 1 \mathrm{H}, J 11.50 \mathrm{~Hz}), 6.52(\mathrm{~d}, 1 \mathrm{H}, J 14.84$ $\mathrm{Hz}), 6.63(\mathrm{~d}, 1 \mathrm{H}, J 15.95 \mathrm{~Hz}), 6.66(\mathrm{dd}, 1 \mathrm{H}, J 10.74,14.18 \mathrm{~Hz}), 6.70$ $(\mathrm{m}, 1 \mathrm{H}), 6.71(\mathrm{dd}, 1 \mathrm{H}, J 11.26,14.62 \mathrm{~Hz}), 6.72(\mathrm{dd}, 1 \mathrm{H}, J 10.80,14.23$ $\mathrm{Hz}), 7.09(\mathrm{~d}, 1 \mathrm{H}, J 15.77 \mathrm{~Hz}), 7.56(\mathrm{dm}, 2 \mathrm{H}, J 8.61 \mathrm{~Hz}), 8.16(\mathrm{dm}, 2 \mathrm{H}$, $J 8.83 \mathrm{~Hz}$ ). Satisfactory elemental analyses were obtained. High resolution EIMS, $\mathrm{m} / z$ calc. for $\mathrm{C}_{37} \mathrm{H}_{45} \mathrm{NO}_{2}:$ 535.3442. Found: 535.3450 even although it is 6 atoms longer. This low value can be explained by the nitrophenyl acceptor containing a stabilizing aromatic group which hinders the formation of the chargeseparated form of the molecule and hence reduces the polarizability and therefore $\beta(0) .{ }^{18}$

In summary, $\beta(0)$ values of aldehyde 1 , dicyanovinyl 2 and nitrophenyl 3 acceptor-substituted $\beta$-apo- 8 '-carotenal chromophores measured by EFISH, are all large in view of the fact that no conventional donor is present, with 2 giving the largest value. The aromatic ring in compound 3 may hinder the formation of the charge-separated state, causing $\beta(0)$ to be greatly reduced.

The work in this paper was performed, in part, by the Center for Space Microelectronics Technology, Jet Propulsion Laboratory, California Institute of Technology and was sponsored by the Strategic Defense Initiative Organization, Innovative Science and Technology Office and The Defense Advanced Research Projects Agency through grant no. 91-NC-146 administered by the Air Force Office of Scientific Research through agreements with the National Aeronautics and Space Administration (NASA). Support from the National Science Foundation (Grant CHE-9106689) is also gratefully acknowledged. S. G. thanks the National Research Council (NRC) and NASA for an NRC Resident Research Associateship at the Jet Propulsion Laboratory. We thank Brian Pierce and Joseph Perry for helpful discussions.

Received, 18th November 1992; Com. 2/06147C

\section{References}

1 S. R. Marder, D. N. Beratan and L.-T. Cheng, Science, 1991, 252, 103.

2 S. R. Marder, L.-T. Cheng and B. G. Tiemann, J. Chem. Soc., Chem. Commun., 1992, 672.

3 S. R. Marder, C. B. Gorman, L.-T. Cheng and B. G. Tiemann, Proc. SPIE, 1992, 1775, in the press.

4 J. J. P. Stewart, J. Comput. Chem., 1989, 10, 209.

5 J. J. P. Stewart, J. Comput. Chem., 1989, 10, 221.

6 B. F. Levine and C. G. Bethea, Appl. Phys. Lett., 1974, 24, 445.

7 L.-T. Cheng, W. Tam, S. H. Stevenson, G. R. Meredith, G. Rikken and S. R. Marder, J. Phys. Chem., 1991, 95, 10631.

8 E. Yang, A. C. Friedli, S. R. Marder and L.-T. Cheng, unpublished results.

9 S. R. Marder, J. W. Perry, G. Bourhill, C. B. Gorman, B. G. Tiemann and K. Mansour, manuscript in preparation.

10 J. B. VanBeek, F. Kajzar and A. C. Albrecht, J. Chem. Phys., $1991,95,6400$

11 M. Blanchard-Desce, I. Ledoux, J.-M. Lehn, J. Malthête and J. Zyss, J. Chem. Soc., Chem. Commun., 1988, 737.

12 M. Barzoukas, M. Blanchard-Desce, D. Josse, J.-M. Lehn and J. Zyss, Chem. Phys., 1989, 133, 323.

13 A. Slama-Schwok, M. Blanchard-Desce and J.-M. Lehn, J. Chem. Phys., 1990, 94, 3894.

14 H. Ikeda, Y. Kawabe, T. Sakai, and K. Kawasaki, Chem. Lett., 1989, 7, 1285.

15 B. S. Furniss, A. J. Hannaford, V. Rodgers, P. W. G. Smith and A. R. Tatchell, Vogel's-Textbook of Practical Organic Chemistry, Longman, New York, 4th edn., 1978, p. 490.

16 W. S. Wadsworth and W. D. Emmons, J. Am. Chem. Soc., 1961, 83, 1733.

17 J. L. Oudar and H. E. Le Person, Opt. Commun., 1977, 66, 2664.

18 B. G. Tiemann, L.-T. Cheng and S. R. Marder, J. Mater. Chem., to be submitted. 